\title{
Wonder and the Digital Double
}

\author{
Brass Art: Chara LEWIS ${ }^{a}$, Kristin MOJSIEWICZ $^{b}$, Anneké PETTICAN ${ }^{c}$ \\ ${ }^{\mathrm{a}}$ Manchester Metropolitan University, England, UK \\ ${ }^{b}$ Edinburgh College of Art, Scotland, UK \\ ${ }^{\mathrm{C}}$ University of Huddersfield, England, UK
}

\begin{abstract}
The collaborative art practice of Brass Art is hybrid, performative and playful. This paper will focus on Brass Art's long-term engagement with 3D body scanning. It will examine how it has been used as a method of self-replication. It will discuss 'the double' in relation to the uncanny and demonstrate how Brass Art have manipulated their personal 3D data to create alter egos, using expressive 3D modelling techniques, moving lights and $3 \mathrm{D}$ printing processes to create installations and precinematic shadowplays. As Marina Warner observes,

"The theme [of the double] is intertwined with technologies of reproduction, first optical, then, increasingly biological. Representation itself acts as a form of doubling: representation exists in magical relation to the apprehensible world, it can exercise the power to make something come alive apparently." [1]

Brass Art will present a series of installations that have been exhibited throughout the UK, including: Moments of Death and Revival (Yorkshire Sculpture Park and Hoxton Square, London), Rooted and Established (Croft Castle, UK) and Inside the Invisible (A Foundation, Liverpool). Brass Art will also discuss a new research project combining crafted digital 3D body scans with museum artefacts that have been duplicated using laser and CT scanning methods. Still Life (No.1) will be exhibited in Dark Matters, Whitworth Art Gallery, Manchester, 2011.
\end{abstract}

The presentation will also discuss future research projects, and reflect upon collaborations with: UK Universities, Industry partners including Wicks and Wilson Ltd, outside agencies including Ogle Models and Prototypes Ltd and RapidformRCA, alongside other creative practitioners.

Keywords: Art, Wonder, Sculpture, Digital, Double, Uncanny, Performance, Installation, Replication, Reproduction, 3D, White Light Scanning, 3D Modelling.

\section{Introduction}

"There is nothing more uncanny than seeing one's face accidently in a mirror by moonlight." [2]

\section{The Double}

The relationship between 3D bodyscanning and the notion of the Digital Uncanny is compelling for us as artists. Our approach to 3D bodyscanning technology is to advance our engagement with 'uncanny' doubling, using white-light based technologies as a tool for capturing and rendering ourselves in three dimensions. The desire to achieve a 3D 'photographic' replication of ourselves akin to a precise body cast, or death mask, and not a subjective representation based on an individual's 'craft' skill, brought us to the threshold of 3D bodyscanning as a possible tool for 'capturing ourselves anew'. As Freud observed,

"The double was originally an insurance against the extinction of the self or, [as Rank puts it] 'an energetic denial of the power of death', and it seems likely that the 'immortal' soul was the first double of the body." [3]

The digital reproduction of our own images in 3D is underpinned by the importance of 'the double' as a concept. In theory, literature and psychoanalysis, the nature of the double is ambiguous, untrustworthy, contrary, and malevolent - only occasionally representing a 'good aspect'. The doubling of a character most often represents a binary opposition, sometimes in the form of an alter ego, revealing the threat to the ego from the double in a psychopathological dimension.

\footnotetext{
ac.lewis@mmu.ac.uk; www.brassart.org.uk

${ }^{b}$ k.mojsiewicz@ed.ac.uk; www.brassart.org.uk

ca.pettican@hud.ac.uk; www.brassart.org.uk
} 
As a representation of the ego, we are interested in the most playful aspect of 'doubling', and how it is performed within our collaborative practice. Over the last ten years of working together, we have used the form of the 'shadow self' to represent this process of ambiguous doubling, and animating static forms (figures, silhouettes, objects) with light to appear live. In this form of shadowplay we increasingly use 3D bodyscanning to create our own doppelgängers. Historian Marina Warner observes that,

"The theme [of the double] is intertwined with technologies of reproduction, first optical, then, increasingly biological. Representation itself acts as a form of doubling: representation exists in magical relation to the apprehensible world, it can exercise the power to make something come alive apparently." [4]

The locus for our 'digital doubles' is diverse: from paper, screen and object to projection. The ontological question - what it is it to be alive - remains at the heart of our playful endeavour, and whilst often flawed, our experimentation is with ourselves as live, imaginative beings simply 'being'.

We are of course aware of the much more complex philosophical terrain that comes with the desire to turn bodies into binary data: the fact that virtual space has become the location for digital copies of human DNA, that biotechnology renders genetic material patentable and technopolitics have both augmented and diminished the body's capacity to act or engage with others. ${ }^{\mathrm{N}}$ Yet our practice remains playful and distinctly human; three figures engaged in the collaborative act of speaking, writing, seeing, hearing, touching, drawing, making, doing; imaginative encounters that record and evoke being alive.
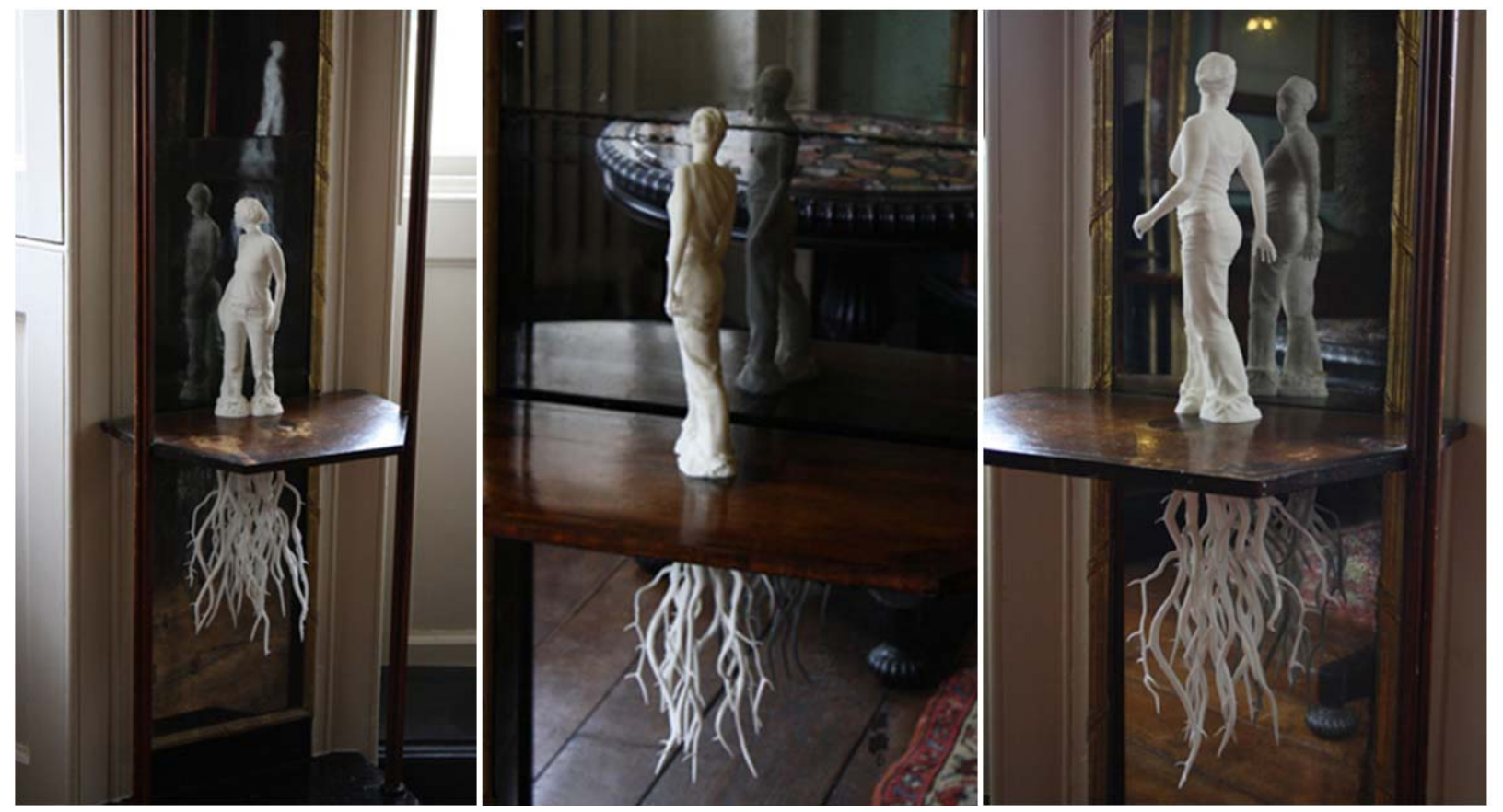

Fig1. Rooted and Established (2009) - installation detail

The three miniature figures that form Rooted and Established (2009) stand gracefully on the shelves of the slender Gothick mirrors of the Ante Room at Croft Castle; framed by their columns and canopies. Despite their decorative air of porcelain ornaments, the figures are 3D prints and exact, miniature replicas of the three artists. As if contemplating their own transformation into small trees, they twist to glimpse their reflection in the tarnished antique mirrors. Narcissus-like they are rooted in one place, eternally self-regarding and absorbed by their own reflection. ${ }^{\text {N2 }}$

\section{Notes:}

${ }^{\mathrm{N} 1}$ For further discussion of this, see: Rivetto, K., (2010) "Digital Uncannies" [5]

${ }^{N} 2$ Rooted and Established (2009) a Meadow Arts Commission for Tell It To The Trees at Croft Castle. 


\section{The Limen}

In our collaborative artwork we return to themes of the double, the in/animate, the miniature and liminal space. Curator David Thorp states that, our practice,

"...always includes the real and the virtual, the hand made and the digital, as Brass Art move seamlessly through time, between pre-cinematic mechanics and new technology." [6]

In doing so, we seek to place ourselves in a cultural frame, exploring ordinary and impossible situations. In Devices of Wonder (2001), Visual Theorist Maria Stafford looks at the cultural intersections between old and new technologies. She states,

"locating emergent private and mass media in the long tradition of optical aids exposes the multiple ways in which humans have been, and continue to be, playfully entangled with their beautiful devices." [7]

Having edited and inserted ourselves into a variety of real and imagined spaces, we began to use performative play as a means to examine the gap between public and private experience. This included replicating ourselves as hand-modelled miniatures, and performing in daylight as shadowy 'trespassers'. Our desire to capture an exact three-dimensional likeness was aroused when we saw the work of German artist Karin Sander. We admired her objective and detached application of the technology and wanted to see whether it was possible to take a more nuanced and subjective view of 3D bodyscanning.

In 2007 the Arts and Humanities Research Council supported a proposal entitled 'Digitised Doubles an enquiry into digital 3D scanning and modelling processes to realise sculptural portraiture exploring poise and character.' The desire to push the limits of the scanning technology resulted in the testing of a number of scanning booths, and we identified Wicks \& Wilson's 3D Triform BodyShape Scanning as the most appropriate. ${ }^{\mathrm{N} 1}$

Timing, speed and quality are intrinsic to the capturing and processing of data in the 3D bodyscanning industry. What made our research proposition unique was our desire to capture the utmost detail in the scanning booth in order to retain as much of 'ourselves' as possible. ${ }^{\text {N2 }}$ Each scan took 8 seconds to fully capture the 8-piece segmented view of the body. In most examples of 3D body scan data the model stands rigid in a classic 'de Vinci pose', arms and legs outstretched. Our engagement with this technology focused on embodiment - to see how accurately we could capture ourselves. We wanted to investigate whether we could scan all three artists at once; which poses fell outside of the 'effective' capture region; what would be invisible to the scanner and how best we could produce dynamic poses whilst attaining least occlusions in the data set. We tried to anticipate where distortions would emerge, and whether these would be of interest to us.
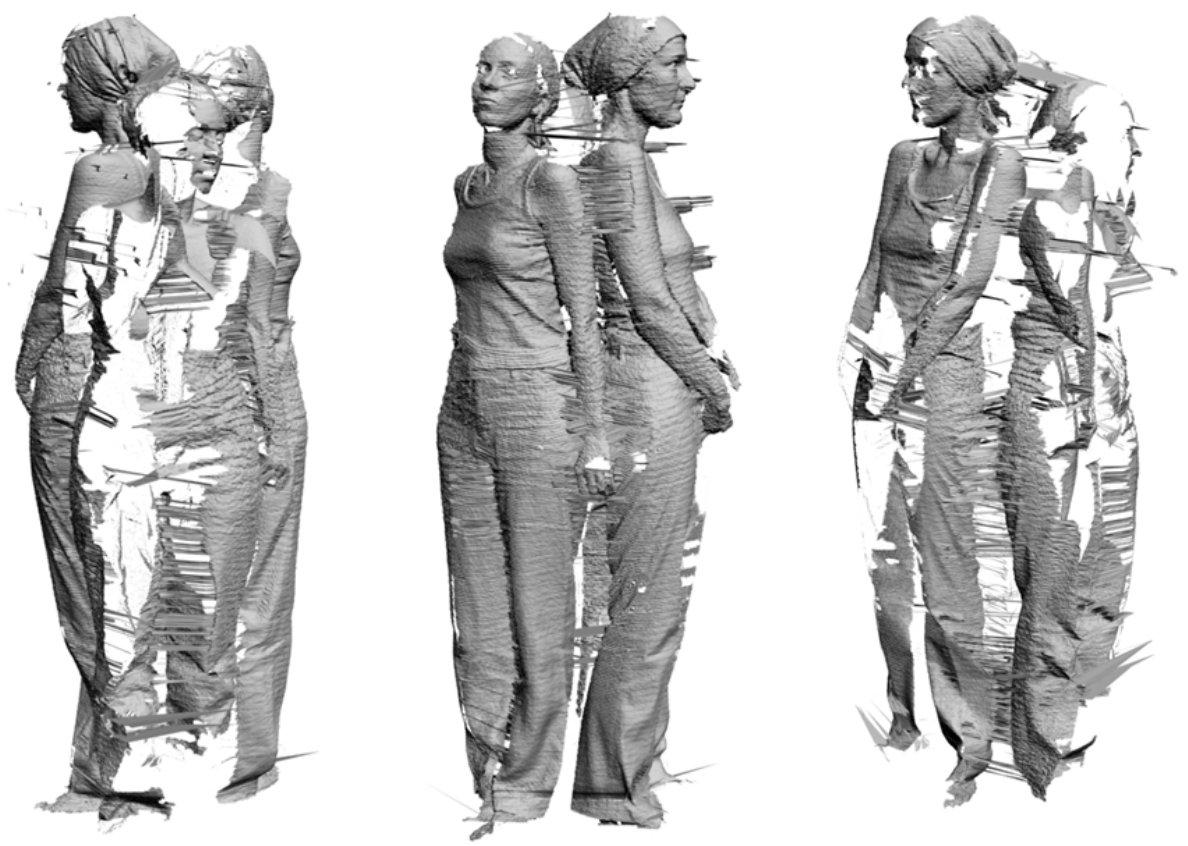

Fig 2. Witness Tree (2009) - test scans 
Pushing our own limitations and that of the scanning technology was key to our 'playful' process - to hold a pose for the required 8 seconds required a certain amount of discipline. It is possible to describe the Triform scan booth as a threshold space - the space between inner and outer worlds - a virtual world, ideal for play and creativity. Psychoanalyst and sociologist Donald Winnicott, in his work on play and transition, makes the claim that,

"It is in the space between inner and outer world, which is also the space between people the transitional space - that intimate relationships and creativity occur." [8]

\section{Notes:}

${ }^{\mathrm{N} 1}$ Wicks \& Wilson, under the stewardship of Stuart Winsborough, kindly sponsored this initial exploration. Original scan tests were performed at London School of Fashion and Glasgow University, School of Computer Science.

$\mathrm{N} 2$ "the potential to reveal public and private aspects of 'the self' - representing both the physiological and psychological aspects of a subject." Digitised Doubles, (Principle Investigator: A. Pettican) AHRC funded.

\section{The Miniature and the Hybrid}

Just as the space of the booth enabled us to step away from reality, and harness the unconscious and dream-like registers of reverie and phantasy, so printing ourselves in miniature has evoked a range of responses. Gallery curator at Yorkshire Sculpture Park, Clare Lilley, notes,

"Nothing has made me realize the perceptual change between a sculpted figure and a 'real' print, formed by the co-ordinates of the artists' bodies, more than these semi-transparent resin figures. They appear to be miniature facsimiles of the artists and at first sight make you blink in disbelief." [9]

To create the installation Moments of Death and Revival $(2008)^{\mathrm{N} 1}$ we posed ourselves in the scanning booth in relation to an imaginary 'virtual counterpart'. These were animals and objects that we perceived would be conjoined with us during the 3D modelling phase ensuring a 'fantastic metamorphosis' between our real body data and something dreamed up and virtually modelled inside a computer. ${ }^{\mathrm{N} 2}$
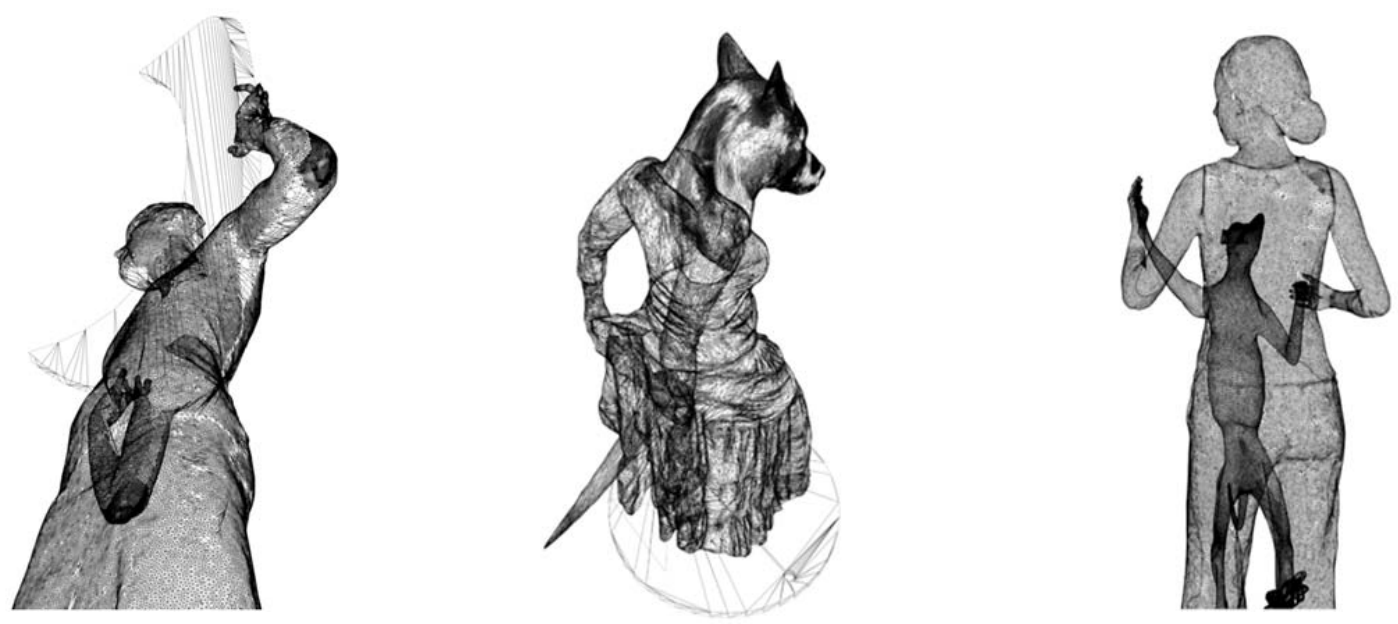

Fig 3. Moments of Death and Revival (2008) - Wireframes selection

Virtual 3D objects were physically incorporated into each portrait to occupy the predefined spaces articulated in the scanning booth. The playful manipulation of the body's anatomical boundaries through metamorphosis coupled with the evolution of individual narrative tableaux, enabled the artists' portraits to shift between the real and the virtual - as they had in our imaginations. It is this virtual suturing that informs our practice and has led to a series of installations including Moments of Death and Revival, Rooted and Established, and Inside the Invisible.

This re-working of the ourselves inside the computer to create a hybrid self is worth further attention. The conjoining of the real and the virtual - first in the physical, semi-theatrical space of the booth, 
then in the virtual space of the computer, and finally in the rendered 3D printed artefact, was a compelling process, one which we both performed and directed. As curator Clare Lilley states,

"Unclassifiable, these hybrids reveal the ways in which Brass Art join the real and the fantastic, observation and the imagination." [10]

\section{Notes:}

${ }^{\mathrm{N} 1}$ Moments of Death and Revival (2008) commissioned for Skyscraping at Yorkshire Sculpture Park.

${ }^{N 2}$ We later imagined ourselves with 'real' objects scanned (like ourselves) from a Museum archive for Still Life (No. 1) (2011)

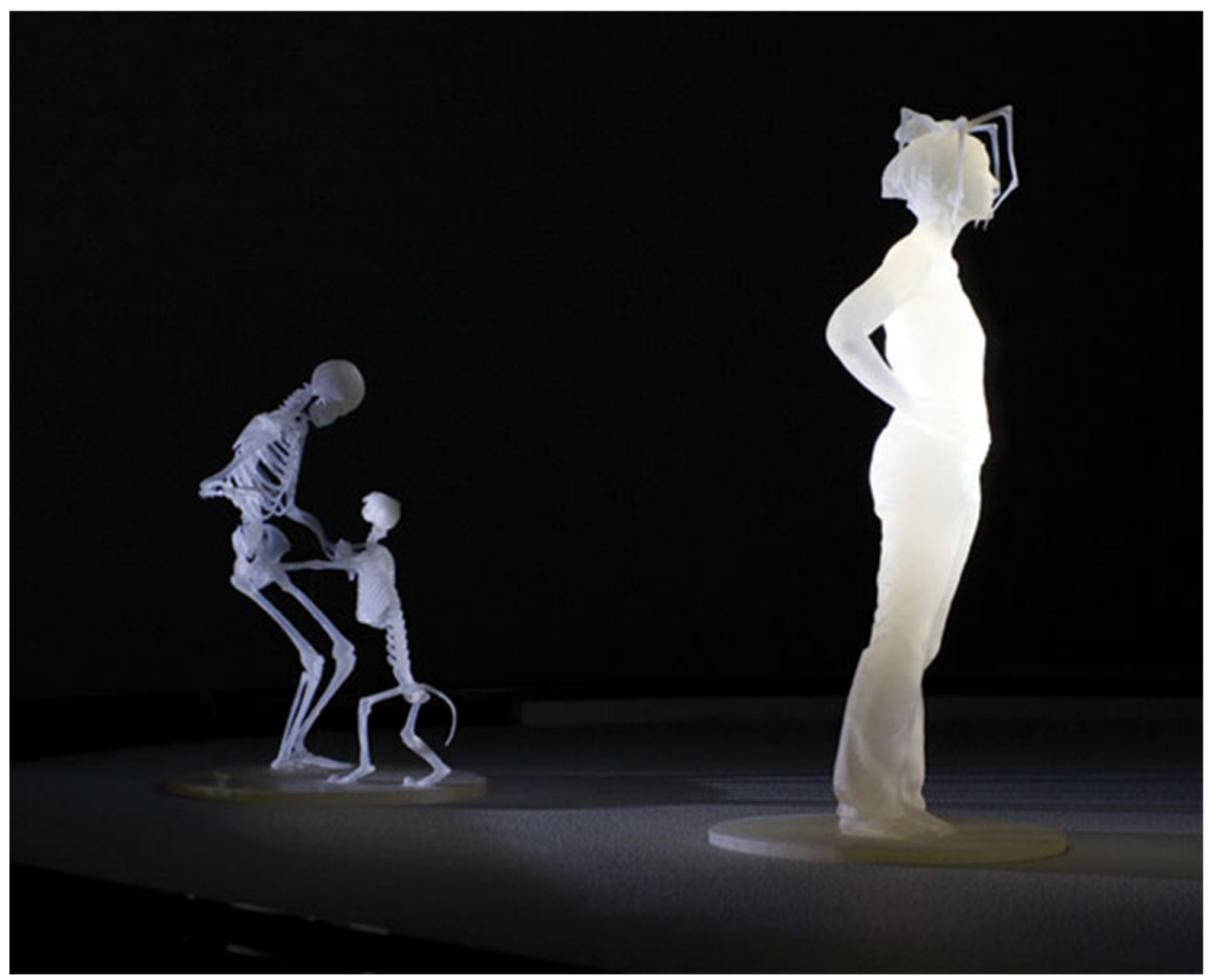

Fig 4. Moments of Death and Revival (2008) - installation detail

\section{The Mimetic}

The concept of mimesis is fundamental to theories of representation and realism. The basic term has remained relatively constant and defined by the early discourse of Plato and Aristotle. ${ }^{\mathrm{N} 1}$ The theory of mimesis opens up the discussion of versimilitude (of seeming-to-be-real) through the notion that in order to recognise something to be an imitation, we first have to be able to perceive a difference between it and the original. Within our collaborative practice, we must consider scale, material, stillness, morphing with relation to replication and doubling.

In the scanning booths we have practiced the stillness required to hold a pose for the requisite capture time. In the gallery installation, the miniature 3D portraits are illuminated in order to throw their shadow forms onto the surrounding walls. These large shadow forms often morph into other figures, objects or animals. 
Mimesis operates at a conscious and unconscious level - the unconscious mimicry of another's manner of speaking, appearance or gesture, is commonplace. The conscious desire to echo, imitate or repeat is balanced by the unconscious 'reverberation' of these influences. To take on the foreignness of the other through imitation, disguise or masquerade, is defined by theorist Kaja Silverman as 'heteropathic' identification. Silverman posits,

"There are two modes of identification: "'heteropathic' where the subject aims to go outside the self, to identify with something / someone / somewhere different, and 'cannibalistic' where the subject brings something other into the self to make it the same." [11]

As part of a collaborative practice we three are represented 'as one' entity. More often there is an attempt to tease out our roles and make distinctions between us. We endeavour to work against this and in doing so, produce space for the loosening of individual identities and the creation of a new collective voice. With a straightforward bodyscan our identities are clear, but the shadow plays formed by our lit, shrunken doppelgängers merge us into forms that cannot be untangled. In our practice it is not unexpected that we would start to iterate each other's gestures and speech patterns over the course of a long collaboration. We have attempted to capture this mimicry in the scanning booth, adopting each other's poses. What has been more surprising are the ways in which our shadows come to resemble each other, and how it is possible to mistake one for another. The ways in which we represent ourselves in our practice has become a way of 'performing' the collaborative process.

Artist-collaborator and Academic, Charles Green posits that,

"[Collaboration] is an active act of individual disappearance, born not out of a desire to break through the limitations of the self but from a desire to neutralize the self in order to clear out a useful, new working space." [12]

\begin{abstract}
5. Notes:
${ }^{\mathrm{N} 1}$ Plato's broad definition suggests that the sciences, the arts and all forms of discourse are mimetic in that they imitate ideal objects. Aristotle's definition of mimesis is narrower than Plato's - he argues that it reflects Man-inaction as portrayed in the form of epic poetry. While Aristotle saw mimesis as 'an inherent instinct for imitation that is a source of both knowledge and pleasure' Plato saw the potential for it to overturn social order and established hierarchies, through mimetic imitation of the role of another citizen. He perceived it as a danger to the social order, which could lead ultimately to the collapse of society itself. [13]
\end{abstract}

\title{
6. Wonder and the Shadow
}

What draws us to the shadow is that in performing, the shadow is both distinctively us, something we recognize (heimlich) and at the same time unfamiliar (unheimlich). This sense of being both familiar and unfamiliar is heightened through the use of props and disguise, enabling others to inhabit our shadow-worlds, standing alongside and between us. Thus the realm of the imagination, in its desire to see these fictive encounters between our selves and 'others' emerge and unfold, is awakened and, through our play, images and ideas emerge.

Our tableaux of 3D figures in Moments of Death and Revival creates a non-linear shadow play: the light and its track are fixed, and the figures positioned and composed, but the shadows themselves loom, grow in scale and seem to overtake each other at different speeds as they pirouette and stalk each other in a 'danse macabre'. ${ }^{\mathrm{N} 1}$ Art Historian Gilda Williams suggests that,

"The shadow too conjures a double merely by virtue of natural phenomena... it is a second hand double, unstable and dark ... it has a doppelgänger-like undesirability in pursuing real, solid bodies." [14]

Initially the function of the travelling light was to seemingly animate and activate the figures by means of their shadows, but the experience of the shadow play itself is that the light appears to reveal the ongoing, unseen activity of the figures - they have come alive apparently and independently. Their subsequent return to the darkness is as uncanny as their re-animation by light. Freud described, "what ought to have remained secret and hidden but has come to light", as pivotal to the notion of the uncanny. [15]

Our 3D hybrid portraits are illuminated by a sudden flash of light and then re-absorbed into the darkness of the gallery, populated by shadows. The repetition of the oscillating light transforms the 
space into a reverie of phantasms, each pursuing, leading, and overtaking the other. These revenants return to perform repeatedly, and appear to alter the speed of each revolution of the shadow play with their presence. Art Historian Louise Milne writes,

"[...] in Brass Art's phantasmagorias, animated shadows have the quality of spatial singularities; they open another dimension inside the photographic world, a dream-like register." [16]

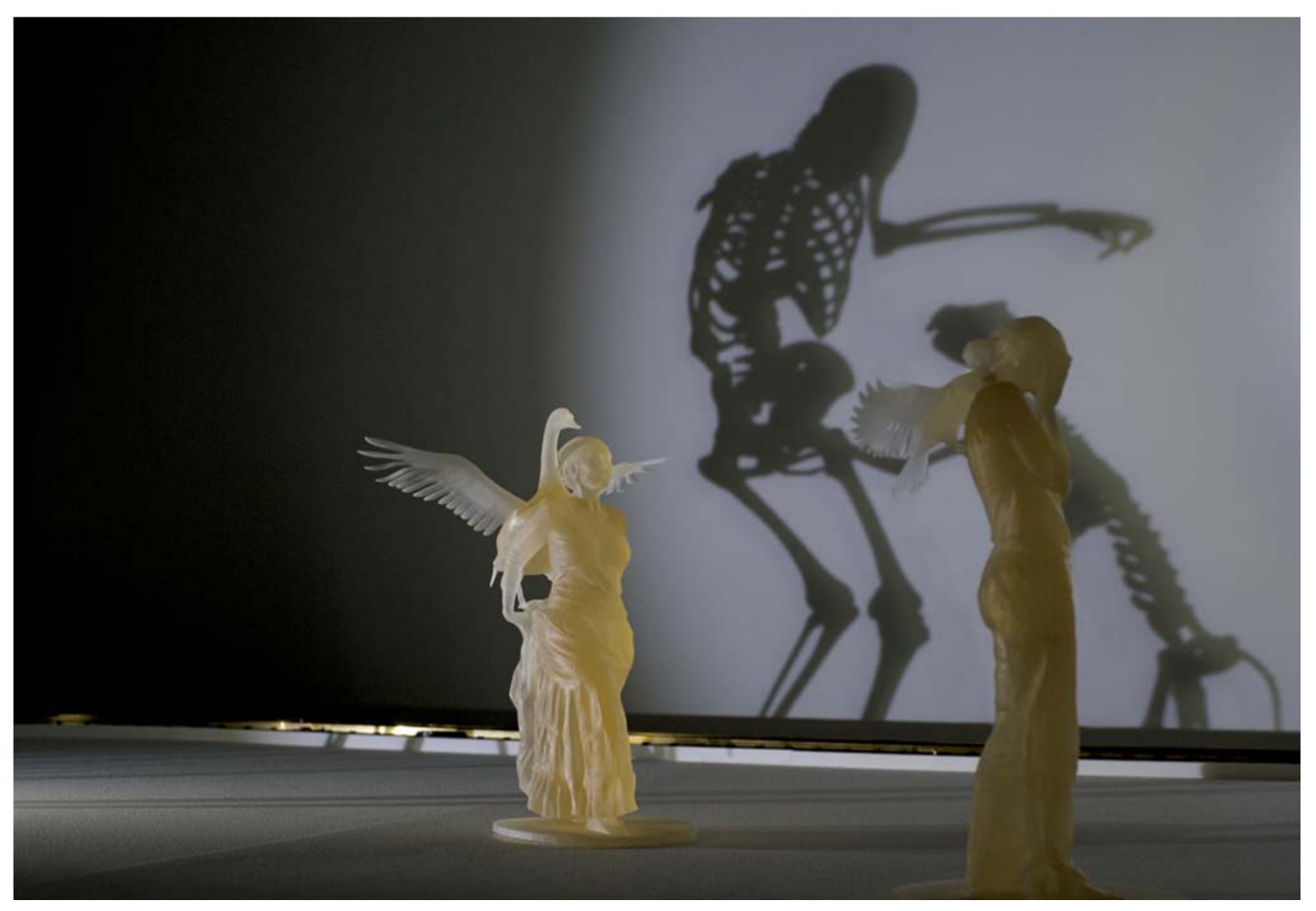

Fig 5. Moments of Death and Revival (2008) - installation detail

To create our most recent installation Still Life (No.1) ${ }^{\mathrm{N} 2}$ we returned again to a Museum archive and placed ourselves in its midst, physically and metaphorically; our sense of wonder comes from the overwhelming quantity of specimens, the surprising juxtapositions and revelations at the turn of a handle or the opening of a drawer. The incongruous, the unexpected; the beauty of raven skeleton's reconstructed integrity, the form of a spider, millions of years old, preserved in amber and held in the hand. The foreign, pervading smell of arrested decay.

The phenomenology of wonder is worthy of exploration as an aspect of our encounter with the museum as well as the audience's experience of the final installation of re-animated objects. ${ }^{\mathrm{N} 3}$ In our age of spectacle it is arguable that a state of wonder can still be achieved in relation to an artwork or museum experience. ${ }^{\mathrm{N} 4}$

As non-scientists we approach the Museum collection with the same wonder as visitors to a Wunderkammern. The Museum collection however, is rigorous regarding provenance: Zoological convention specifies that if a specimen has not been classified within the existing phylum or species in the collection then it is effectively nonexistent and unseen: invisible within the Museum. This double nature appealed to us - the possibility of being essentially 'out of place' - present and unseen at the same time; a method we have applied to our practice over the last ten years. By contrast the Wunderkammern displays,

"...immense collections of "rare" objects, where the natural and the artificial - products of "divine" and human craft, respectively - lived side-by-side as objects of amazement." [17]

Our approach to the Museum collection is admittedly eclectic, not keeping to established taxonomies and classifications, but forming our own collection of curiosities for our own ends. The Wunderkammern and subsequent 'cabinets of curiosity' represent a set of ideas surpassed by modern scientific knowledge. In this sense we are resurrecting the obsolete, juxtaposing it with new technologies and finding the new and the unexpected. Thus in this new installation, objects three 
dimensionally scanned from the museum collection are morphed with our own body data, creating a new ethereal landscape. Silvano Arieti refers to this as 'the tertiary process' -

"Instead of rejecting the primitive (or whatever is archaic, obsolete, or off the beaten path), the creative mind integrates it with normal logical processes in what seems a 'magic synthesis' from which the new, the unexpected, and the desirable emerges." [18]

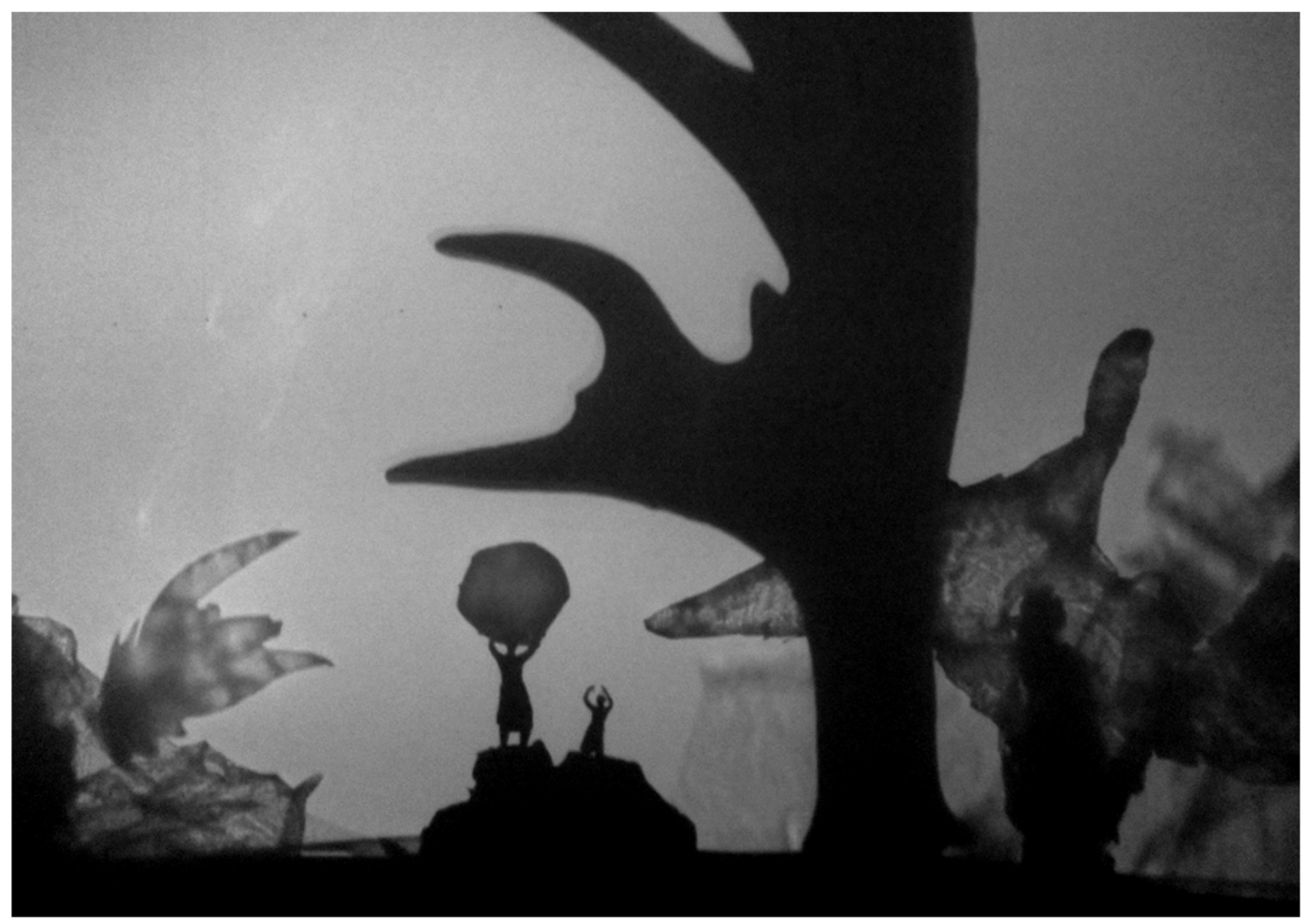

Fig 6. Still Life (No.1)(2011) - installation detail (in progress)

Still Life (No.1) incorporates more delicate, temporary and translucent elements to create shadows and unexpected plays of light. Ordinary cellulose wrapping is transformed into shadows, which belie their flimsy origins, and in turn create a shimmering light play. There is a sense of the Kantian Sublime ${ }^{N 5}$ in relation to the gigantic scale of shadow achieved in the installation space, and the integration of our small printed figures into a landscape, orbited by a light, evoking the cosmos. The sense of wonder, which originated in the museum, is played out in the continuous transformations and shifting relationships cast up by the light. In direct reference to the heavens and our historical relationship to its signs, a comet is harnessed as a kite held by one of the figures. This 'haired star', is described by Writer and Curator Lisa Le Feuvre as,

"... a sign mistaken for a wonder, be that cataclysm or rapture, and a figure of looping obsession. It is something that is always with us, no matter that it is sometimes far out of sight." [19]

\section{Notes:}

${ }^{\mathrm{N} 1}$ The Danse Macabre / Dance of Death connected the dead and the living, and depicted Death dancing with all classes of the population. Here we refer more to the imagery of Holbein, and the separate narratives of each dancer confronting his, or her, death, or mortality. See: Milne, L. (2007) "Carnival and Dreams" [20]

${ }^{N 2}$ Still Life (No.1) (2011) commissioned by Whitworth Art Gallery for Dark Matters.

N3 'The experience of astonishment before the world and the beginning of philosophy'. Plato and Aristotle held the investigation of thaumazein, wonder at the fact of the world, to be the beginning of Philosophy. [21]

${ }^{\mathrm{N} 4}$ Easily dismissed as the stuff of fairy stories or cabinets of curiosity, Wonder was explored by the fathers of philosophy as a textual phenomenon associated with pleasure at the end of poetry and the essential element in a literary act.

N5 "Immanuel Kant in Critique Of Judgement (1790) also set out to explore what happens at the borderline where reason finds its limits. He [...] deepened the shift of focus initiated by Burke, by asserting that the sublime was not so much a formal quality of some natural phenomenon as a subjective conception - something that happens in the mind. He thereby shifted the analysis towards the impact and consequence of the sublime experience upon consciousness, and argued that the sublime was essentially about a negative experience of limits." [22] 


\section{The Temporal Body}

Shadows are never static, shifting as the light moves. The inherent movement or animation of shadows ties us most closely to the experience of film viewing - and all film is by definition a form of animation. In early cinema screenings the film-maker / projectionist would hold a still frame for a few seconds at the start of the film. The audience, lulled by the familiarity of the photographic image would be terrified by its sudden animation. ${ }^{\mathrm{N} 1}$

In early film the movie camera quickly became a moving camera and thus a means of 'transporting' the viewer. Implicit in this transportation is also an emotional movement. Frame by frame, the editor ${ }^{\mathrm{N} 2}$ controls the flow and the visual ruptures in the film: collaging tiny clips to become a composite image, animating the stilled frames into life and conversely freezing moments into tableaux. The inanimate 'made flesh' is a ghostly return of the revenants that return to the living world as cinematic phantasms. Visual Theorist Giuliana Bruno observes,

"Suddenly their faces no longer move. They are frozen, arrested on the editing table." [23]

The connection here between the editing table and the anatomical table is germane to our practice. The 3D data we have captured through the photographic body scanning process is fragmented, stitched and sutured back into a composite whole form. In Anatomy Acts (2006) Roberta McGrath claims that,

"[...] modern 'virtual' technologies of dissection and mass circulation cannot be understood without the physical work of anatomical dissection." [24]

The anatomical dissection, originally referencing the blood and guts of cutting and revealing, can now also be understood in the contemporary virtual processes of ortho-slicing, x-rays and MRI scans. The dissection, whether virtual or real, invokes the spectacle of death. The desire to film, on the other hand, conveys the longing to capture life, and so to traverse and explore the form, we need to first approach it frame by frame.

There is a symmetry between this filmic process of editing and suturing, and with the Visible Human Project $(\mathrm{VHP})^{\mathrm{N} 3}$ in which slice by slice, two human subjects (male and female) were captured and recomposed, to be studied as medical specimens. In her paper on this subject, Catherine Waldby states that, in this way, "No domain of experience, no matter how personal or particular, seems immune to translation into data." [25] Clearly the process of revealing such complete and detailed interiority can only be achieved once dead. Here then, Waldy continues,

"the body exists simultaneously as a rational object of science and an uncanny form of digital existence, located ambiguously in virtual space between the living and the dead." [26]

The temporal nature of the virtual body is fascinating. It can be traversed, looked at inside out, passed through and stacked in time. Historically, artists have used their body as a site for close-up observation ${ }^{\mathrm{N} 4}$ or surveillance in artworks produced whilst the subject is alive. Our animated video work Inside the Invisible refutes this curiosity - returning to our virtual counterparts, we re-imagined the conjoined body of artist and animal as a grid like carapace. The digitisation of the body through the $3 \mathrm{D}$ bodyscanning process causes the interior of the body to become invisible, and therefore hollow. As a result, the skin itself becomes a permeable membrane, navigable as both an external and internal landscape. The virtual camera moves from exterior to interior: from object to subject. It is not however an interior of organs and flesh - the interior is the underside of the exterior data $-\mathrm{a}$ negative landscape. 

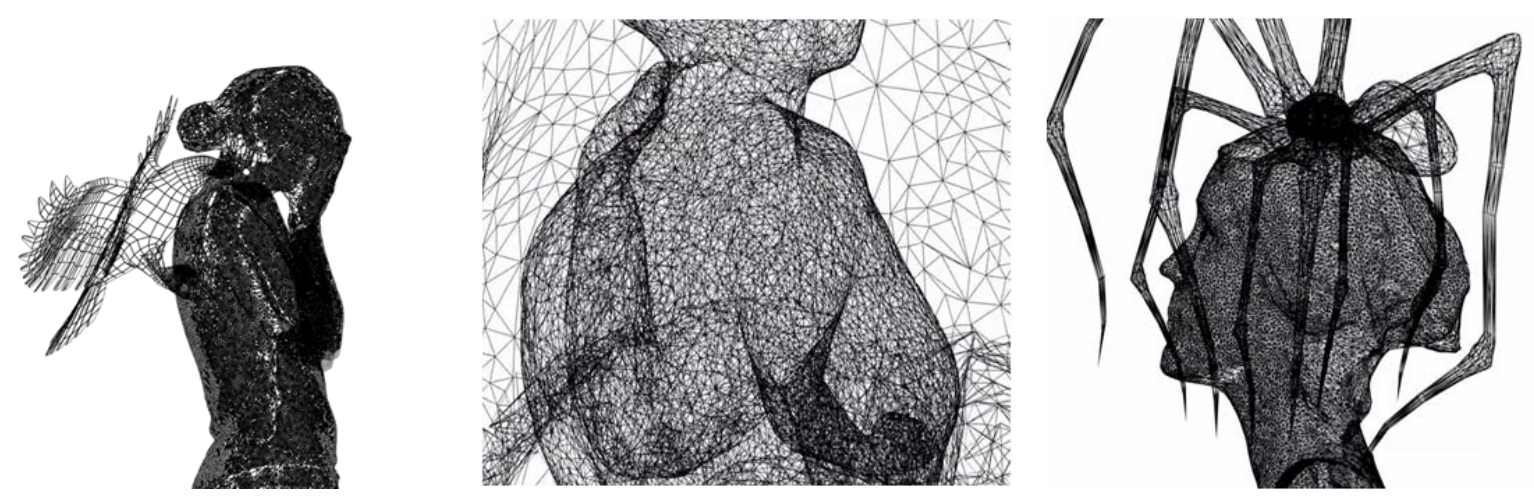

Fig 7. Inside the Invisible (2010) - 3 screen video piece

Reflecting on the significance of the empty interior body, we return to the notion of the limen - the inbetween spaces sited amid the physical world and the realm of the imagination. The filmic mobility of a virtual 3D camera enables a re-animation of the data: through our agency, the camera skimmed imagined 'surfaces' and hung, suspended, in cavernous interiors - a sculptural hollow.

\author{
7. Notes: \\ ${ }^{\mathrm{N} 1}$ We wanted to draw a parallel with the editing process in montage film and the body in space, specifically in \\ Dziga Vertov's 1929 film Man with a Movie Camera. In this seminal film, a single day in Moscow is represented \\ but made, or composed, in 4 cities over a time span of 4 years. The concept of such a heavily mediated \\ composite 'masquerading' as a whole entity appealed to us and to our use of new technologies. We have in the \\ past been accused of being 'brutal' and forcing technological applications to bend to our needs - Vertov's desire \\ to control and impose new and possible realities through editing and montage seems to us to be a parallel \\ process. \\ ${ }^{N} 2$ One of the most interesting sections of the film shows Vertov's female editor, Elisaveta Svilova, cutting and \\ splicing back together the actual filmstrips. Svilova is seen as the architect of the film - the seamstress with the \\ scalpel, composing and shaping the film in a decidedly tactile, concrete way. \\ ${ }^{\mathrm{N} 3}$ Visible Human Project (VHP) - a digital anatomical atlas, created by the National Library of Medicine in \\ Maryland, USA in 1994. [27] \\ ${ }^{N 4}$ Such as Mona Hatoum's endoscopic video work Corps Étranger (1994)
}

\title{
8. The (w)hole
}

Our continued fascination with lens based tools, which allow us to capture ourselves faithfully, has recently led us to research the possibilities of shadow play and drawing using new gaming technologies. ${ }^{\mathrm{N} 1}$ In our practice, being both present, and at the same time absent from the work, is an important and recurring motif. There is a 'ghosting' of ourselves in our latest work, Shadow Worlds Writers' Rooms (2011-) in which we capture both a physical space and also a transient performance that takes place within the heart of that space. We were drawn to 'the glass town country' - an imaginative realm created by the Brontë's as children. Using photography as a means to capture our presence in the Brontë Parsonage in Haworth, we saw an opportunity to extend this work and capture the whole scene. Like a play within a play, the mise-en-abyme captured ourselves, the photographer and the site. ${ }^{\mathrm{N} 2}$

The system provided full body 3D motion capture under ambient light conditions. In addition, the inbuilt practical ranging limits were ideal for the proportions of the Brontë Parsonage as they are designed to fit domestic gaming spaces. Furthermore, the custom built software not only proffers the opportunity to capture the scene but also to later watch, angle, zoom and edit the material drawn by laser animation. The initial Kinect scan images produced suggested the potential to create an extension of our shadow play. Shadows in each scene are created by lack of data (holes) as one object obstructs the laser allowing a void to form beyond or behind it. It is our intention is to use our custom built software to examine these shadowy spaces. 

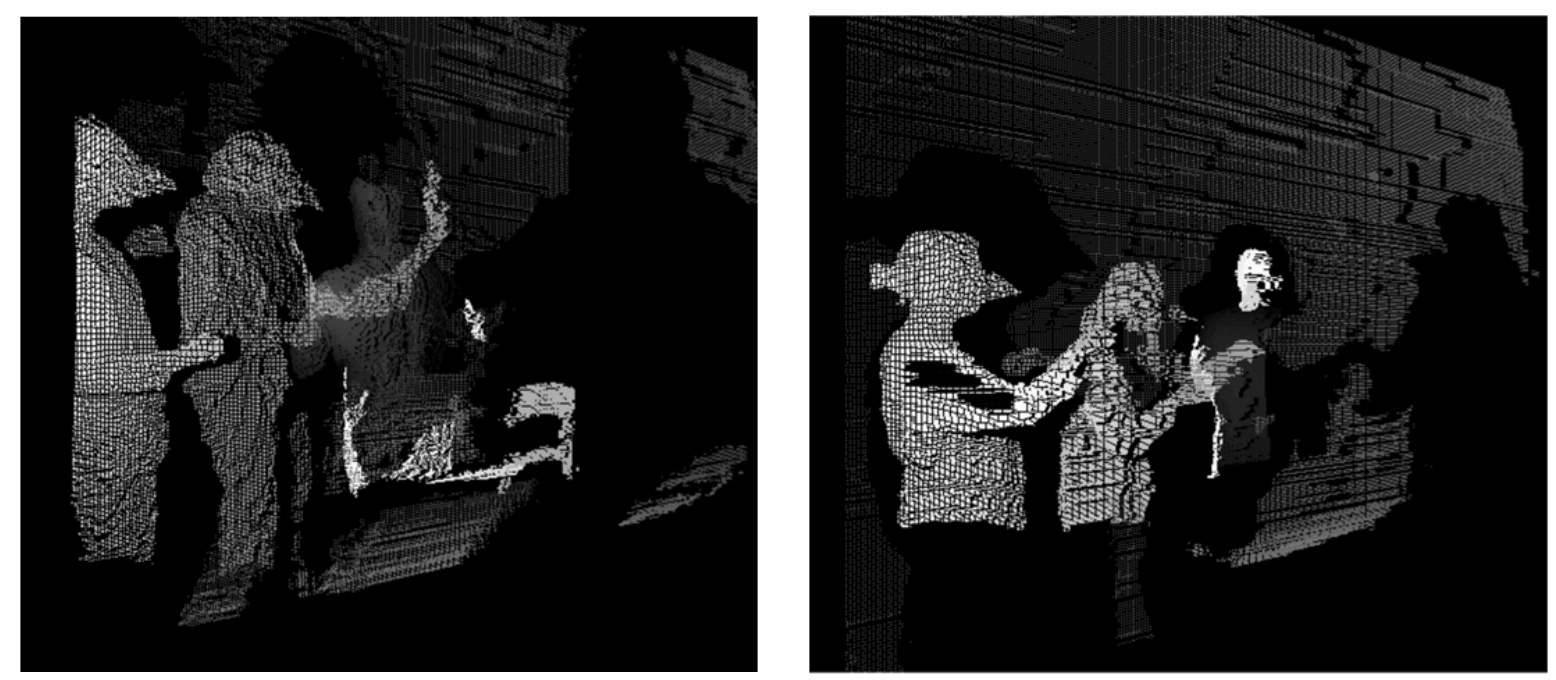

Fig 8. work in progress - Kinect scan images

\section{Notes:}

${ }^{\mathrm{N} 1}$ Microsoft's Kinect sensor and on-range camera technology

${ }^{\mathrm{N} 2}$ We used custom built software created by Spencer Roberts along with Microsoft's Kinect sensor. Photography by Simon Pantling.

\section{References:}

1. Warner, M., (2004): "Fantastic Metamorphoses and Other Worlds", Vintage, p.165.

2. Heine, H., (1826): "Die Harzreise", quoted in Royle, N., (2003): "The Uncanny", Manchester University Press, p.345.

3. Freud, S., (2003): "The Uncanny", Penguin Books, (London), p.142.

4. Warner, M., (2004) ibid

5. Rivetto, K., (2010): "Digital Uncannies: Surveillance and Sensory Technologies" (accessed: 17/09/11) http://edinburgh.academia.edu/KrissRavetto/Blog/4450/Figures-of-the-VisceralConference-University-of-Edinburgh

6. Thorp, D., (2008): "Brass Art. Beside Themselves" in "Brass Art: Skyscraping", Yorkshire Sculpture Park, p. 29.

7. Stafford, M., (2001): "Devices of Wonder", Getty Publications, (Los Angeles), p.2

8. Winnicott, D., (1953): "Transitional Objects And Transitional Phenomena" in "International Journal of Psycho-Analysis", 34:89-97

9. Lilley, C., (2008): "Brass Art: Skyscraping", Yorkshire Sculpture Park, p.11.

10. Lilley, C., (2008) ibid

11. Silverman, K., quoted by Rendell, J. (2001): "Travelling the Distance/Encountering the Other", in: Blamey, D., ed. (2002): "Here, There, Elsewhere: Dialogues on Location and Mobility", Open Editions, (London) p.24.

12. Green, C., (2004): "Doubled: Five Collaborations", Cabinet, issue 14 (Doubles), p.71.

13. Macey, D., (2001): "Penguin Dictionary of Critical Theory", Penguin Books (London), p.254

14. Williams, G., (2000): "On the Double", Lowry Press (Manchester)

15. Royle, N., (2003): "The Uncanny", Manchester University Press, (Manchester), p.345.

16. Milne, L., (2008) "The Broom of the System" exhibition essay, Tramway, (Glasgow).

17. Olalquiaga, C., (2005): "Object Lesson/Transitional Object", Cabinet, issue 20 (Ruins)

18. Arieti, S., (1976): "Creativity: The Magic Synthesis", Basic Books (New York). p.186.

19. Le Feuvre, L., \& Morton, T., (2010) "The British Art Show 7: In the Days of the Comet", Hayward Publishing, (London), p.9.

20. Milne, L., (2007): "Carnivals and Dreams: Pieter Bruegel and the History of the Imagination", Mutus Liber, (London), p.526.

21. Kingwell, M., (2000): "Husserl's Sense of Wonder" in "The Philosophical Forum", vol 31, issue 1, pp. 85-107.

22. Morley, S., ed. (2010): "Documents of Contemporary Art: The Sublime", Whitechapel/MIT, pp.15-16. 
23. Bruno, G., (2002): "Atlas of Emotion: Journeys in Art, Architecture, and Film", Verso (New York), p.25

24. McGrath, R., (2006): "Moving Pictures: Gender and the Visualisation of Life", in: Patrizio, A. \& Kemp, D., eds. (2006) "Anatomy Acts: How We Come to Know Ourselves", Birlinn, (Edinburgh), p.63.

25. Waldby, C., (1996): "Revenants: The Visible Human Project and the Digital Uncanny" (accessed: 17/09/11) http://wwwmcc.murdoch.edu.au/ReadingRoom/VID/Uncanny.html

26. Waldby, C., ibid

27. Visible Human Project: http://www.nlm.nih.gov/research/visible/visible human.html

\section{Acknowledgements:}

3D Modelling: James Carmichael, Jenni Colquhoun, Ricardo Creemers, Reuben Fleming, Alison Mealey, Chris Norval, Daniel Roberts, Adam Shepherd, Teabag Studios

3D Bodyscanning: Jeni Bougourd - London College of Fashion, Dr Paul Siebert, Rachel Lo \& Susanne Oehler - Department of Computer Science, University of Glasgow, Stuart Winsborough Wicks \& Wilson

3D Scanning: Anne Marie Lapensee - Liverpool Museums Conservation, Richard Massey -

Department of engineering services, Manchester Metropolitan University

3D Printing Prototypes: Simon Dunning - University of Huddersfield

3D Printing Sponsorship: 3D Systems, Ogle Models and Prototypes Ltd, RapidForm RCA

3D Printing Specialists: Steve Willmott \& team - Ogle Models and Prototypes Ltd

Material Sponsorship: 3D Systems, EOS, Huntsman

Technical \& Artistic Collaborators: Monty Adkins, Anthony Hall, Simon Pantling, Jay Payne, Andy

Plant, Spencer Roberts

Ticiana Correra - The A Foundation, Arts Council England, Jenna Holmes - Brontë Parsonage, Friends of Yorkshire Sculpture Park, Paulette Terry Brien \& Laurence Lane - The International3, Anne de Charmant \& Mandy Fowler - Meadow Arts, Clare Lilley \& Sarah Coulson - Yorkshire Sculpture Park, Helen Stalker - Whitworth Art Gallery, David Gelsthorpe \& Dmitri Logunov - University of Manchester Museum. Association of Art Historians, Arts \& Humanities Research Council, Edinburgh College of Art, Manchester Metropolitan University, University of Huddersfield.

\section{List of Artworks:}

Moments of Death and Revival (2008) 3D printed objects in acrylic polymer, dimensions: $19 \mathrm{~cm}$ to $25 \mathrm{~cm}$ high. Version 1: 9 figures, 3 morph figures, 2 skeletons, train, track, lights, plinths. Commissioned by Yorkshire Sculpture Park for Skyscraping at Yorkshire Sculpture Park, Bretton Hall, UK. 3D material and print sponsorship: 3D Systems.

Rooted and Established (2009) 3 SLS figures in nylon prime part. Commissioned by Meadow Arts for Tell it to the Trees at Croft Castle, Ludlow, UK. 3D material \& print sponsorship: EOS and Ogle Models and Prototypes Ltd.

Witness Tree (2009) sprayed SLS print in nylon prime part, in wood \& glass housing. Commissioned by Meadow Arts for Tell it to the Trees at Croft Castle, Ludlow, UK. 3D material \& print sponsorship: EOS and Ogle Models and Prototypes Ltd. Permanently installed at Coningsby Hospital, Hereford.

Inside the Invisible (2010) 3-screen video installation. Each consecutive video 5 mins, 15 mins total. Audio commissioned by A Foundation - Brass Art \& Monty Adkins. Economy of the Gift at A Foundation, Liverpool, UK.

Still Life (No.1) (2011) Installation: $2 \mathrm{~m}$ table with revolving arm and light. 9 SLA figures and antlers. Cellophane, paper and props. 3D material sponsorship: Hunstman. 3D print sponsorship: Ogle Models and Prototypes Ltd. Commissioned by Whitworth Art Gallery for Dark Matters at Whitworth Art Gallery, Manchester, UK.

Shadow Worlds Writers' Rooms (2011-) in progress. Large-scale photographs - Brass Art \& Simon Pantling. Kinect video - Brass Art \& Spencer Roberts. Brontë Parsonage, Haworth, UK. 